\title{
Melatonin affects the dynamic steady-state equilibrium of estrogen sulfates in human umbilical vein endothelial cells by regulating the balance between estrogen sulfatase and sulfotransferase
}

\author{
ALICIA GONZÁLEZ, CARLOS MARTÍNEZ-CAMPA, CAROLINA ALONSO-GONZÁLEZ and SAMUEL COS \\ Department of Physiology and Pharmacology, School of Medicine, University of Cantabria \\ and Valdecilla Biomedical Research Institute (IDIVAL), ES-39011 Santander, Spain
}

Received April 27, 2015; Accepted September 25, 2015

DOI: $10.3892 /$ ijmm.2015.2360

\begin{abstract}
Melatonin is known to reduce the growth of endocrine-responsive breast cancers by interacting with estrogen signaling pathways. Estrogens play an important role in breast cancer, but also in various types of tissues, including vascular tissue. Estrogen sulfatase (STS) converts inactive estrogen sulfates into active estrogens, whereas estrogen sulfotransferase (EST) sulfonates estrogens to estrogen sulfates. Therefore, STS and EST are considered to be involved in the regulation of local estrogen levels in hormone-dependent tumors and in non-pathologic tissues, such as those of the vascular system. Estrogens have a major impact on the vasculature, influencing vascular function, the expression of adhesion proteins, angiogenesis and the inflammatory state. In this study, we investigated the status of STS and EST in human umbilical vein endothelial cells (HUVECs) and the modulatory effects of melatonin. Both STS and EST were highly expressed in the HUVECs. The enzymatic activity correlated with the expression levels in these cells. Our findings also demonstrated that melatonin, at physiological concentrations, modulated the synthesis and transformation of biologically active estrogens in HUVECs through the inhibition of STS activity and expression, and the stimulation of EST activity and expression. Since melatonin decreased the STS levels and increased the EST levels, it modified the dynamic steady-state equilibrium of estrogen sulfates by increasing the inactive estrogen levels and decreasing the active estrogen levels. Therefore, melatonin may modulate the known different biological actions of estrogens in endothelial cells, as well as in estrogen-dependent tumors and non-pathologic tissues.
\end{abstract}

Correspondence to: Dr Samuel Cos, Department of Physiology and Pharmacology, School of Medicine, University of Cantabria, Avenida Cardenal Herrera Oria s/n, ES-39011 Santander, Spain

E-mail: coss@unican.es

Key words: melatonin, human umbilical vein endothelial cells, estrogens, sulfatase, estrogen sulfotransferase, estrogen sulfates

\section{Introduction}

The local metabolism and synthesis of estrogens, resulting from the interactions of various enzymes, is considered to play a crucial role in the pathogenesis and development of hormone-dependent carcinomas, but also in various organs and systems, including female reproductive organs, bone, liver, central nervous system and vascular system (1-3). The major circulating form of plasma estrogen is estrone sulfate, a biologically inactive form of estrogen, which acts as an estrogen reserve, which can be formed from sulfated estrogens by steroid sulfatase (STS), which is present in both normal and tumor tissues (Fig. 1). The plasma concentrations of estrogen sulfates are 50- to 15-fold higher than those of unconjugated estrogens, such as estrone, estradiol and estriol, and their half-life in plasma (10-12 h) is considerably longer than that of estrone and estradiol (20-30 min) (4,5). Estrogen sulfates are therefore thought to act as a reservoir for the formation of active estrogens via the action of STS (6), which converts inactive estrogen sulfates to estrone and $17 \beta$-estradiol. Estrone is then reduced to the biologically active estrogen, $17 \beta$-estradiol, by $17 \beta$ '-hydroxysteroid dehydrogenase type 1 (17 $\beta$-HSD1) (7). STS is ubiquitously expressed in mammalian tissues and target organs, including the liver, endometrium, ovaries, bone, brain, prostate, white blood cells and adipocytes, but it is particularly prevalent in the placenta and in breast carcinomas $(6,7)$. The potency of estrogenic hormones is generally reduced during the metabolic process to inactive products in target tissues, and this contributes to the modulation of the overall biological actions of estrogens. Estrogen sulfotransferase (EST) sulfonates estrogens to form biologically inactive estrogen sulfates (8) and it is distributed in a wide range of normal human tissues, such as the kidneys, liver, gastrointestinal tract, vascular tissue and breasts (Fig. 1). In breast carcinoma, EST activity and expression tend to be decreased (9). Therefore, STS and EST are considered to be involved in the regulation of in situ estrogen levels in various human tissues and hormone-dependent tumors $(6,10)$.

Melatonin, the main secretory product of the pineal gland, is well known to reduce the growth and development of estrogenresponsive breast cancers (11-14). Melatonin exerts its oncostatic effects in hormone-dependent breast cancer by interfering at 
different levels of the estrogen signaling pathways $(15,16)$. One of the mechanisms through which this occurs involves the regulation by melatonin of the expression and activity of several enzymes (aromatase, STS, 17 $\beta$-HSD1 and EST) that are responsible for the local synthesis of estrogens; thus, melatonin functions as a selective estrogen enzyme modulator $(17,18)$. Melatonin exerts its regulatory actions on estrogen-producing enzymes in tumor cells, surrounding fibroblasts and endothelial cells. In endothelial cells, melatonin regulates the aromatase pathway, which transforms androgens into estrogens (19-21). Melatonin reduces the activity and expression of aromatase mainly by inducing a significant downregulation in aromatase expression, specifically driven by promoter I.7, the major promoter directing aromatase expression in endothelial cells (19). In addition, melatonin has been shown to exert anti-angiogenic effects by reducing endothelial cell proliferation, invasion, migration and tube formation, through a downregulatory effect on vascular endothelial growth factor (VEGF) in endothelial cells $(22,23)$. These results piqued our interest into the possible effects of melatonin on other enzymes involved in the local biotransformation of steroids in endothelial cells. Thus, our objective in the present study, was to analyze the activity and expression of EST and STS in human umbilical vein endothelial cells (HUVECs) and to elucidate the possible modulatory effects and mechanisms of melatonin.

\section{Materials and methods}

Cells and culture conditions. The HUVECs were purchased from the American Tissue Culture Collection (ATCC; Rockville, MD, USA). They were maintained as monolayer cultures in $75 \mathrm{~cm}^{2}$ plastic culture flasks in Vascular Cell Basal Medium (VCBM) supplemented with Endothelial Cell Growth kit-BBE (both from ATCC) which consisted of $2 \%$ fetal bovine serum (FBS), $0.2 \%$ bovine brain extract, $5 \mathrm{ng} / \mathrm{ml}$ recombinant human epidermal growth factor (rhEGF), $10 \mathrm{mM} \mathrm{L}$-glutamine, $0.75 \mathrm{U} / \mathrm{ml}$ heparin sulfate, $1 \mu \mathrm{g} / \mathrm{ml}$ hydrocortisone hemisuccinate, $50 \mu \mathrm{g} / \mathrm{ml}$ ascorbic acid, penicillin $(20 \mathrm{U} / \mathrm{ml})$ and streptomycin $(20 \mu \mathrm{g} / \mathrm{ml})$ (Sigma-Aldrich, Madrid, Spain) at $37^{\circ} \mathrm{C}$ in a humid atmosphere containing $5 \% \mathrm{CO}_{2}$. To avoid genetic mutation and low viability, HUVECs at no more than 6 passages were used in the following experiments.

Measurement of STS activity. STS activity in the HUVECs was assayed by the formation of estrone from a labeled substrate $\left(\left[6,7-{ }^{3} \mathrm{H}(\mathrm{N})\right]\right.$-estrone sulfate ammonium salt) (24). The HUVECs were seeded onto $75 \mathrm{~cm}^{2}$ plastic culture flasks in VCBM supplemented with $2 \%$ FBS. When a homogenous monolayer of pre-confluent HUVECs was established, the medium was aspirated and the cultured cells were harvested and seeded onto 6 -well plates $\left(3 \times 10^{5}\right.$ cells/well) in VCBM supplemented with $2 \%$ FBS. One day later, the medium was replaced with fresh medium ( $1 \mathrm{ml} /$ plate) containing $20 \mathrm{nM}\left[6,7-{ }^{3} \mathrm{H}(\mathrm{N})\right]$-estrone sulfate ammonium salt (NEN Life Science Products, Boston, MA, USA) $(57.3 \mathrm{Ci} / \mathrm{mM})$ in the presence of either $1 \mathrm{mM}$, $1 \mu \mathrm{M}$ or $1 \mathrm{nM}$ melatonin, or its diluent (control; ethanol at a final concentration $<0.001 \%$ ). Following $20 \mathrm{~h}$ of incubation, the culture dishes were placed on ice for $15 \mathrm{~min}$ to condense any water vapour and $0.5 \mathrm{ml}$ of the medium was transferred to tubes containing $2.5 \mathrm{ml}$ of toluene, vortexed for $45 \mathrm{sec}$ and centrifuged at $1,000 \mathrm{x}$ for $10 \mathrm{~min}$ at $4^{\circ} \mathrm{C}$. The resulting organic phase was added to vials with scintillation cocktail (National Diagnostics, Atlanta, GA, USA) and counted using a beta counting system (Beckman LS60001C Scintillation Counter; Beckman Instruments, Atlanta, GA, USA). The amount of radioactivity measured in the $\left[{ }^{3} \mathrm{H}\right]$-toluene was corrected by subtracting the blank values from each sample, obtained by incubating dishes containing medium but no cells with the tritiated estrone. As previously described (18), the values were also corrected by taking into account the fractional retention of tritium in medium throughout the procedure of incubation and processing, utilizing parallel dishes containing medium plus known amounts of $\left[{ }^{3} \mathrm{H}\right]$ estrone (NEN Life Science Products). The fractional retention of tritium in medium throughout the incubation and processing of samples was always $>92 \%$.

Measurement of EST activity. EST activity in the HUVECs was evaluated by the formation of $\mathrm{E}_{1}-\mathrm{S}$ from $\left[2,4,6,7-{ }^{3} \mathrm{H}(\mathrm{N})\right]$-estrone, as previously described (25). The HUVECs were seeded onto $75 \mathrm{~cm}^{2}$ plastic culture flasks in VCBM supplemented with $2 \% \mathrm{FBS}$. When a homogenous monolayer of pre-confluent HUVECs was reached, the medium was aspirated and the cultured cells were harvested and seeded onto 6 -well plates $\left(3 \times 10^{5}\right.$ cells/well) in VCBM supplemented with $2 \%$ FBS. One day later, the medium was replaced with fresh medium $(1 \mathrm{ml} /$ plate $)$ supplemented with $2 \%$ dicyclohexylcarbodiimide (DCC), containing $2 \mu \mathrm{M}$ estrone including $10 \mathrm{nM}\left[2,4,6,7-{ }^{3} \mathrm{H}(\mathrm{N})\right]$-estrone (NEN Life Science Products) (100 Ci/mM), 7 mM MgCl 2,50 mM Tris- $\mathrm{HCl} \mathrm{pH} 7.4$, phosphoadenosine phosphosulfate (PAPS) at a final concentration of $20 \mu \mathrm{M}$, in the presence of either melatonin $(1 \mathrm{mM}, 1 \mu \mathrm{M}$ or $1 \mathrm{nM}$ ), or its diluent (control; ethanol at a final concentration $<0.001 \%$ ). Following $48 \mathrm{~h}$ of incubation, the medium was transferred to tubes containing a cold mix of $4 \mathrm{ml}$ of chloroform plus $0.375 \mathrm{ml}$ of $0.25 \mathrm{M}$ Tris- $\mathrm{HCl} \mathrm{pH} \mathrm{8.7,} \mathrm{vortexed} \mathrm{for} 45 \mathrm{sec}$ and centrifuged at $600 \mathrm{xg}$ for $5 \mathrm{~min}$ at $4^{\circ} \mathrm{C}$. The resulting aqueous phase was added to vials with scintillation cocktail and counted using a beta counting system. Values were corrected for blanks and tritium recovery $(>87 \%)$ was as described above.

Measurement of mRNA expression of STS and EST. The mRNA expression of different enzymes was carried out by reverse transcription-quantitative polymerase chain reaction (RT-qPCR) of the HUVECs, after incubation of cells with either melatonin or the vehicle for $4 \mathrm{~h}$, as described in a previous study of ours (39). Total cellular RNA was purified using the NucleoSpin RNA II kit (Macherey-Nagel GmbH \& Co., Düren, Germany) following the manufacturer's instructions. The integrity of the RNA was assessed by electrophoresis in ethidium bromidestained $1.2 \%$ agarose-Tris-borate EDTA gels. The absorbance ratio A260/A280 $\mathrm{nm}$ was $>1.8$. For cDNA synthesis, $1 \mu \mathrm{g}$ of total RNA was denaturated at $65^{\circ} \mathrm{C}$ for $10 \mathrm{~min}$ and reverse transcribed for $50 \mathrm{~min}$ at $45^{\circ} \mathrm{C}$ using the cDNA synthesis kit (Bioline, London, UK) in a final volume of $20 \mu \mathrm{l}$ in the presence of $500 \mathrm{ng}$ of oligo(dT)12-18 primer. qPCR (MX3000; Stratagene, La Jolla, CA, USA) was performed using Brilliant SYBR-Green PCR Master Mix (Stratagene) following the manufacturer's instructions. The pairs of human oligonucleotides (Sigma Genosys Ltd., Cambridge, UK) used as primers are indicated in Table I. S14 mRNA expression was used as a control. PCRs were performed for 40 cycles for quantitative analysis using the annealing temperature indicated in Table I 
Table I. Primers used for the amplification of mRNA transcripts of STS, EST and S14 (control).

\begin{tabular}{llccc}
\hline mRNA & \multicolumn{1}{c}{ Sequence } & bp & [ ] nM & T \\
\hline STS & F: 5'-TCCGTTCCTGCTTGTCTTGTC-3' & 197 & 200 & $57^{\circ} \mathrm{C}$ \\
& R: 5'-CCTGGTCCGATGTGAAGTAGATG-3' & & 200 & $57^{\circ} \mathrm{C}$ \\
EST & F: 5'-AGACTCATTTGCCACCTGAACTTC-3 & 133 & 200 & $59^{\circ} \mathrm{C}$ \\
& R: 5'-GGATGACCAGCCACCATTAGAAAG-3' & & 100 & $59^{\circ} \mathrm{C}$ \\
S14 & F: 5'-TCACCGCCCTACACATCAAAC-3' & 159 & 100 & \\
& R: 5'-TCCTGCGAGTGCTGTCAGAG-3' & & 100 & \\
\hline
\end{tabular}

bp, product size (base-pairs); [ ] nM, primers concentration; T, annealing temperature; F, sense (forward) primer; R, antisense (reverse) primer; STS, steroid sulfatase; EST, estrogen sulfotransferase.

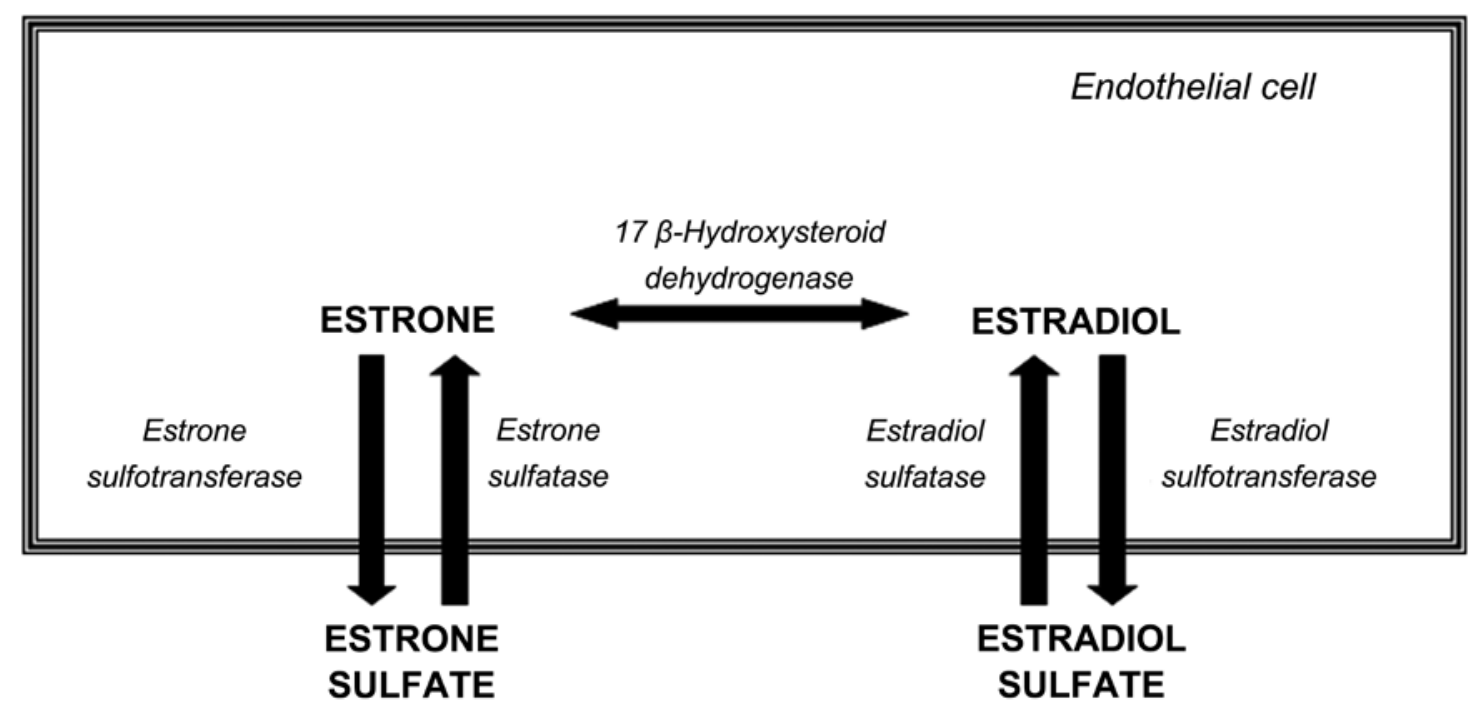

Figure 1. Schematic diagram representing the enzymatic mechanisms involved in the local formation and transformation of estrogens in endothelial cells. Estrogen sulfates act as a reservoir for the formation of active estrogens and their concentration depends on the action of sulfatase, which hydrolyzes biologically inactive estrogen sulfates to active estrogens (estrone and estradiol), and estrogen sulfotransferase which sulfonates estrogens to biologically inactive estrogen sulfates.

for $60 \mathrm{sec}$, the extension being carried out at $72^{\circ} \mathrm{C}$ for $45 \mathrm{sec}$ and the denaturation at $95^{\circ} \mathrm{C}$ for $50 \mathrm{sec}$. Each product was electrophoresed on ethidium bromide-stained $2 \%$ agarose-Tris-borate gels to corroborate that the product amplified corresponded to the adequate length. Finally, the mRNA expression levels of target genes were normalized to S14 mRNA expression. Each reaction was run in triplicate. Melting curve analysis was performed using dissociation curves to verify that only a single product with no primer-dimers was amplified.

Statistical analysis. The data are expressed as the means \pm standard errors of the mean (SEM) of 6 independent experiments. Statistical differences between groups were analyzed by one way analysis of variance (ANOVA), followed by the StudentNewman-Keuls test. Results were considered statistically significant difference at a value of $\mathrm{p}<0.05$.

\section{Results}

Effects of melatonin on STS activity and expression. We first examined the effects of various concentrations of melatonin on the activity and mRNA expression of STS.Physiological concentrations of melatonin $(1 \mathrm{nM})$ induced a significant $(\mathrm{p}<0.001)$ inhibition of STS activity in the HUVECs (Fig. 2A). The concentrations of melatonin in the micromolar range $(1 \mu \mathrm{M})$ were also effective at reducing $(\mathrm{p}<0.001)$ the conversion of estrone sulphate to estrone.

With the aim of determining whether the inhibitory effects of melatonin on STS activity are due to the downregulation of STS expression, we incubated the HUVECs with either melatonin $(1 \mathrm{mM}, 1 \mu \mathrm{M}$ or $1 \mathrm{nM})$ or the vehicle [the diluent (control), ethanol at a final concentration $<0.001 \%$ ] for $4 \mathrm{~h}$, and total RNA was isolated to perform RT-qPCR with specific primers for human STS. As a control, the same samples were subjected to RT-qPCR with specific primers for the housekeeping gene, $\mathrm{S} 14$, a ribosomal protein component of the $40 \mathrm{~S}$ subunit. Treatment of the HUVECs with physiological concentrations of melatonin $(1 \mathrm{nM})$ led to a significant and potent inhibition (40\%) of STS mRNA expression compared to the controls (Fig. 2B). The supraphysiological concentrations of melatonin $(1 \mu \mathrm{M})$ were also effective at reducing $(\mathrm{p}<0.001)$ STS mRNA expression. 

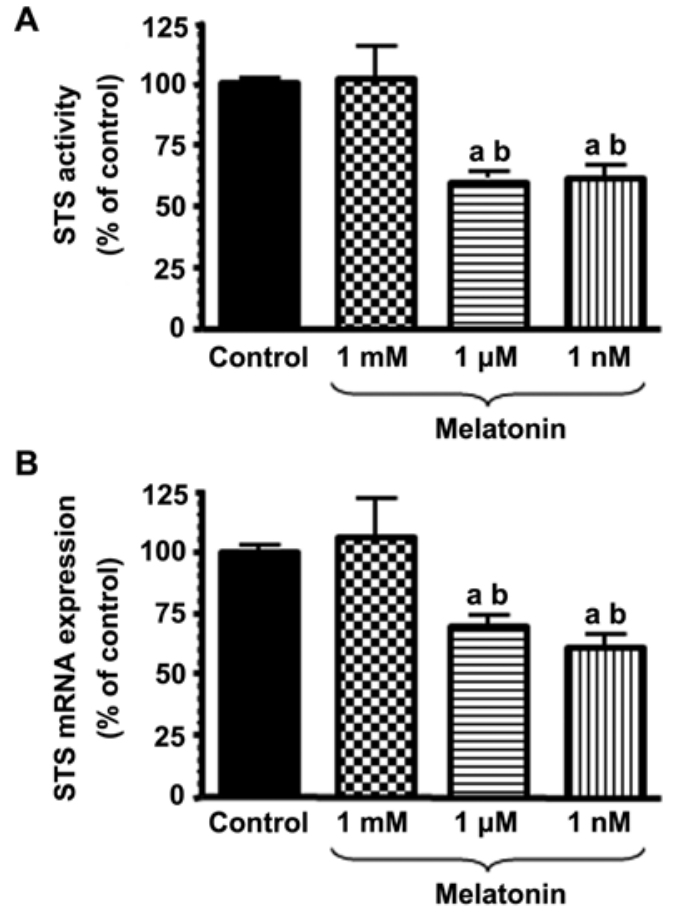

Figure 2. (A) Effects of melatonin ( $1 \mathrm{mM}, 1 \mu \mathrm{M}$ or $1 \mathrm{nM}$ ), or its diluent (control, ethanol at $0.001 \%$ final concentration) on basal estrogen sulfatase (STS) activity in human umbilical vein endothelial cells (HUVECs), determined after $20 \mathrm{~h}$ of incubation with the indoleamine. (B) Effects of melatonin $(1 \mathrm{mM}, 1 \mu \mathrm{M}$ or $1 \mathrm{nM}$ ), or its diluent on STS mRNA expression in HUVECs. Cells were incubated with melatonin or ethanol $(0.001 \%)$ (control) for $4 \mathrm{~h}$. Data are expressed as the percentage of the control group (means \pm SEM). ${ }^{a} \mathrm{p}<0.001$ vs. control; ${ }^{\mathrm{b}} \mathrm{p}<0.001$ vs. melatonin $1 \mathrm{mM}$.

A
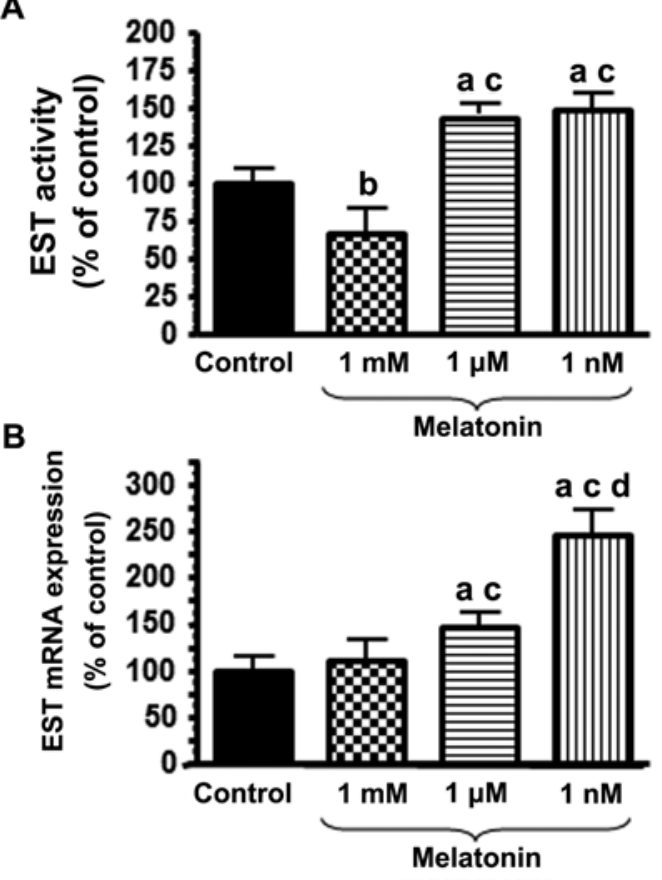

Figure 3. (A) Effects of $48 \mathrm{~h}$ of incubation with melatonin ( $1 \mathrm{mM}, 1 \mu \mathrm{M}$ or $1 \mathrm{nM}$ ) or its diluent (control, ethanol at $0.001 \%$ final concentration) on estrogen sulfotransferase (EST) activity in human umbilical vein endothelial cells (HUVECs). (B) Effects of melatonin ( $1 \mathrm{mM}, 1 \mu \mathrm{M}$ and $1 \mathrm{nM})$, or its diluent on the mRNA expression of EST in HUVECs. Cells were incubated with melatonin or ethanol $(0.001 \%)$ (control) for $4 \mathrm{~h}$. Data are expressed as the percentage of the control group (means $\pm \mathrm{SEM}$ ). ${ }^{\mathrm{a}} \mathrm{p}<0.001$ vs. control; ${ }^{\mathrm{b}} \mathrm{p}<0.01$ vs. control; ${ }^{c} \mathrm{p}<0.001$ vs. melatonin $1 \mathrm{mM} ;{ }^{\mathrm{d}} \mathrm{p}<0.001$ vs. melatonin $1 \mu \mathrm{M}$.

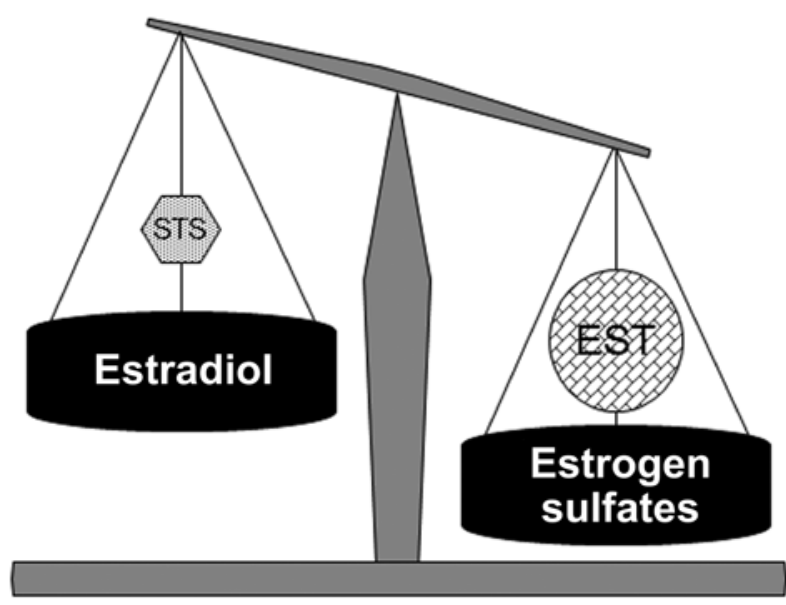

Figure 4. Melatonin tends to activate and overexpress estrogen sulfotransferase (EST) and to decrease sulfatase (STS) activity and expression, which alters the dynamic steady-state equilibrium of estrogen sulfates and may result in the accumulation of estrogen sulfates in human umbilical vein endothelial cells (HUVECs).

Effects of melatonin on EST activity and expression. In a second set of experiments, the effects of melatonin on the activity and mRNA expression of EST were examined. The activity of EST was significantly stimulated by treatment of the HUVECs with physiological concentrations $(1 \mathrm{nM})$ of melatonin (Fig. 3A). When the HUVECs were incubated for $4 \mathrm{~h}$ with $1 \mathrm{nM}$ melatonin, the mRNA expression of EST was significantly increased $(\mathrm{p}<0.001)$ (Fig. 3B). Higher concentrations of melatonin $(1 \mu \mathrm{M})$ also induced an increase in the mRNA expression of EST, although to a lesser extent than that triggered by treatment with $1 \mathrm{nM}$ melatonin (Fig. 3B).

\section{Discussion}

Estrogens are potent steroid hormones with pleiotropic effects potentially causing diverse modulatory effects on vascular functions and the endothelial dysfunction that is associated with an increased risk of cancer and cardiovascular disease (26-28). Estrogens synthesized in peritumoral endothelial cells also play a role in the growth and progression of estrogen-dependent tumors, such as breast tumors (4). Estrogens are secreted primarily by the ovaries, the placenta and the testes, and they are also produced by peripheral steroidogenic conversion. Two major pathways are implicated in providing peripheral sources of estrogen in human peripheral tissues. One is the aromatase pathway which transforms androgens into estrogens $(29,30)$, and the other is the sulfatase pathway which converts estrogen sulfates into estrogens by the enzyme, STS (5). During the past decades, research has been directed mainly towards the development of aromatase inhibitors (31), and as a result, potent, well-tolerated and highly selective aromatase inhibitors are now available for use in clinical practice (32). However, there is a growing awareness of the role that STS may play in regulating the formation of estrogenic steroids since the estrone sulfatase pathway is the major route of estrogen formation in breast tumors $(6,33)$. Estrone sulfate is quantitatively the most important precursor of estradiol and STS activity is 40-500-fold greater than aromatase activity in breast cancer 
tissues. Whereas STS decreases estrogen sulfate levels and increases active estrogen levels, EST sulfonates estrogens to biologically inactive estrogen sulfates and increases the level of estrogen sulfates $(4,9,34)$.

Melatonin is well known for its oncostatic properties $(11,12,14,16)$. This indoleamine exerts its oncostatic effects on estrogen-dependent breast tumors mainly through two mechanisms: interfering with the estrogen signaling pathways at the estrogen receptor level $(16,35,36)$ and regulating the activity and expression of the enzymes involved in local estrogen biosynthesis in tumor cells and peritumoral fibroblasts $(16,20,21,37,38)$.

To date, it has not been clearly determined whether STS and EST activity and expression are present in HUVECs. The present study firstly demonstrated that STS and EST are expressed in HUVECs, and are able to modulate the concentration of estrogen sulfates, and therefore, estrogen synthesis in endothelial cells. Melatonin, at physiological (1 nM) concentrations, induced a significant inhibition of STS activity in the HUVECs and this inhibitory effect was due to the downregulation of STS expression. To the best of our knowledge, this is the first time that the effects of melatonin on STS activity and expression in endothelial cells have been established. In relation to the modulatory effects of melatonin on STS, it is known that melatonin inhibits STS activity and expression in vitro in human breast cancer cells (18) and glioma cells (39). This modulatory effect of melatonin on STS has also been described in vivo, in rats bearing 7,12-dimethylbenz[a]anthracene (DMBA)-induced mammary tumors (40). The inhibition of STS activity and expression in breast cancer with high doses of synthetic antiestrogens, such as tamoxifen, has been also described (41).

Estrogen sulfate concentrations are dependent on its inactivation by STS and its production by EST (balance of STS/EST). Recently, it has been described that EST is highly expressed in human vascular endothelial and smooth muscle cells and the modulation of its activity and expression regulates the levels of active estrogens in these cells, thereby affecting the physiology and pathophysiology of vascular walls $(42,43)$. In this study, physiological concentrations of melatonin (1 nM) significantly increased EST activity and expression in HUVECs. This upregulation of EST induced by melatonin has also been described in human breast cancer cells $(9,18,20)$. This indolamine, at physiological concentrations in human breast cancer cells, increased EST activity by almost 2-fold and EST expression up to 3 -fold $(9,18,20)$. These results concur with the findings of other previous on estrogen-responsive human breast cancer cells. Melatonin was shown to exert a direct concentration-dependent anti-proliferative effect and only melatonin concentrations closer to $1 \mathrm{nM}$ (concentrations similar to those found in the serum of most mammals during the nocturnal period) were effective at decreasing cell proliferation, whereas supra- or subphysiological concentrations lacked these antiproliferative effects $(11,12,14)$.

STS and EST are involved in the regulation of in situ estrogen sulfate levels in HUVECs. The balance between these two enzymes determines the concentration of estrogen sulfates and consequently, the concentration of active estrogens in endothelial cells $(4,6)$. In normal breast tissue, STS activity and expression are very weak whereas, the activity and expres- sion of EST are very high. The equilibrium between the two enzymes is displaced towards the accumulation of estrogen sulfates, the major precursor of local estrogen production. However, in breast carcinoma tissue the formation of the active $17 \beta$-estradiol predominates, as STS tends to be overexpressed, whereas the expression of EST is frequently decreased $(4,9)$. In HUVECs, since melatonin decreases the activity and expression of STS, which transforms the estrone sulfates to estrogens, and increases the activity and expression of EST, which inactivates estrogens, it results in the modification of the dynamic steadystate equilibrium of estrogen sulfates by increasing estrogen sulfate levels and decreasing active estrogen levels (Fig. 4). Melatonin regulates the activity and expression of the enzymes involved in the local synthesis of estrogens in endothelial cells in a similar manner to the activity and expression of enzymes in normal mammary normal tissue.

In conclusion, the findings presented herein point to a role for melatonin in mediating the synthesis and transformation of biologically active estrogens in HUVECs by inhibiting the mRNA expression and activity of the enzyme involved in estradiol formation (STS) and by stimulating the mRNA expression and activity of the enzyme responsible for the inactivation of estradiol and formation of the biologically inactive estrogen sulfates (EST). Melatonin decreased STS and increased EST levels, and as a result, modified the dynamic steady-state equilibrium of estrogen sulfates through increased estrogen sulfate levels and decreased active estrogen levels. Thus, melatonin may modulate the physiology and pathophysiology of vascular tissue.

\section{Acknowledgements}

This study was supported by grants from the Spanish Science Technology and Innovation Ministry (SAF2010-19579 and SAF2013-42012-P) and a grant from the Instituto de Investigación Valdecilla (IDIVAL) (APG/12).

\section{References}

1. Germain D: Estrogen carcinogenesis in breast cancer. Endocrinol Metab Clin North Am 40: 473-484, 2011.

2. Pelekanou V and Leclercq G: Recent insights into the effect of natural and environmental estrogens on mammary development and carcinogenesis. Int J Dev Biol 55: 869-878, 2011.

3. Russo J and Russo IH: The role of estrogen in the initiation of breast cancer. J Steroid Biochem Mol Biol 102: 89-96, 2006.

4. Pasqualini JR and Chetrite GS: Recent insight on the control of enzymes involved in estrogen formation and transformation in human breast cancer. J Steroid Biochem Mol Biol 93: 221-236, 2005.

5. Stanway SJ, Delavault P, Purohit A, Woo LW, Thurieau C, Potter BV and Reed MJ: Steroid sulfatase: a new target for the endocrine therapy of breast cancer. Oncologist 12: 370-374, 2007.

6. Pasqualini JR: The selective estrogen enzyme modulators in breast cancer: a review. Biochim Biophys Acta 1654: 123-143, 2004.

7. Suzuki T, Miki Y, Nakamura Y, Moriya T, Ito K, Ohuchi N and Sasano H: Sex steroid-producing enzymes in human breast cancer. Endocr Relat Cancer 12: 701-720, 2005.

8. Suzuki T, Miki Y, Nakata T, Shiotsu Y, Akinaga S, Inoue K, Ishida T, Kimura M, Moriya T and Sasano H: Steroid sulfatase and estrogen sulfotransferase in normal human tissue and breast carcinoma. J Steroid Biochem Mol Biol 86: 449-454, 2003.

9. Cos S, González A, Álvarez-García V, Alonso-González C and Martínez-Campa C: Melatonin and breast cancer: selective estrogen enzyme modulator actions. In: Advances in Cancer Drug Targets. Atta-ur-Rahman (ed). Vol 1. Bentham Science Publishers, Sharjah, UAE, pp207-237, 2013. 
10. Sasano H, Suzuki T, Nakata T and Moriya T: New development in intracrinology of breast carcinoma. Breast Cancer 13: 129-136, 2006.

11. Cos S and Sánchez-Barceló EJ: Melatonin and mammary pathological growth. Front Neuroendocrinol 21: 133-170, 2000.

12. Cos S and Sánchez-Barceló EJ: Melatonin, experimental basis for a possible application in breast cancer prevention and treatment. Histol Histopathol 15: 637-647, 2000.

13. Hill SM and Blask DE: Effects of the pineal hormone melatonin on the proliferation and morphological characteristics of human breast cancer cells (MCF-7) in culture. Cancer Res 48: 6121-6126, 1988.

14. Blask DE, Sauer LA and Dauchy RT: Melatonin as a chronobiotic/anticancer agent: Cellular, biochemical, and molecular mechanisms of action and their implications for circadian-based cancer therapy. Curr Top Med Chem 2: 113-132, 2002.

15. Sánchez-Barceló EJ, Cos S, Fernández R and Mediavilla MD: Melatonin and mammary cancer: a short review. Endocr Relat Cancer 10: 153-159, 2003.

16. Cos S, González A, Martínez-Campa C, Mediavilla MD, Alonso-González C and Sánchez-Barceló EJ: Estrogen-signaling pathway: a link between breast cancer and melatonin oncostatic actions. Cancer Detect Prev 30: 118-128, 2006.

17. Cos S, González A, Martínez-Campa C, Mediavilla MD, Alonso-González C and Sánchez-Barceló EJ: Melatonin as a selective estrogen enzyme modulator. Curr Cancer Drug Targets 8: 691-702, 2008.

18. González A, Cos S, Martínez-Campa C, Alonso-Gonzalez C, Sánchez-Mateos S, Mediavilla MD and Sánchez-Barcelo EJ: Selective estrogen enzyme modulator actions of melatonin in human breast cancer cells. J Pineal Res 45: 86-92, 2008.

19. Álvarez-García V, González A, Martínez-Campa C, Alonso-González C and Cos S: Melatonin modulates aromatase activity and expression in endothelial cells. Oncol Rep 29: 2058-2064, 2013.

20. Cos S, Martínez-Campa C, González A, Álvarez-García V, Alonso-González C, Mediavilla MD and Sánchez-Barceló EJ Melatonin and aromatase in breast cancer. Clin Cancer Drug 1: 54-64, 2014.

21. Cos S, Alvarez-García V, González A, Alonso-González C and Martínez-Campa C: Melatonin modulation of crosstalk among malignant epithelial, endothelial and adipose cells in breast cancer (Review). Oncol Lett 8: 487-492, 2014.

22. Alvarez-García V, González A, Alonso-González C, Martínez-Campa C and Cos S: Regulation of vascular endothelial growth factor by melatonin in human breast cancer cells. J Pineal Res 54: 373-380, 2013.

23. Alvarez-García V, González A, Alonso-González C, Martínez-Campa C and Cos S: Antiangiogenic effects of melatonin in endothelial cell cultures. Microvasc Res 87: 25-33, 2013

24. Duncan L, Purohit A, Howarth NM, Potter BV and Reed MJ: Inhibition of estrone sulfatase activity by estrone-3-methylthiophosphonate: A potential therapeutic agent in breast cancer. Cancer Res 53: 298-303, 1993.

25. Falany CN, Krasnykh V and Falany JL: Bacterial expression and characterization of a cDNA for human liver estrogen sulfotransferase. J Steroid Biochem Mol Biol 52: 529-539, 1995.

26. Barnabas $\mathrm{O}$, Wang $\mathrm{H}$ and Gao XM: Role of estrogen in angiogenesis in cardiovascular diseases. J Geriatr Cardiol 10: 377-382, 2013.

27. Chakrabarti S, Morton JS and Davidge ST: Mechanisms of estrogen effects on the endothelium: An overview. Can J Cardiol 30: 705-712, 2014
28. Khalil RA: Estrogen, vascular estrogen receptor and hormone therapy in postmenopausal vascular disease. Biochem Pharmacol 86: 1627-1642, 2013.

29. Bulun SE, Lin Z, Imir G, Amin S, Demura M, Yilmaz B, Martin R, Utsunomiya H, Thung S, Gurates B, et al: Regulation of aromatase expression in estrogen-responsive breast and uterine disease: from bench to treatment. Pharmacol Rev 57: 359-383, 2005

30. Bulun SE, Chen D, Lu M, Zhao H, Cheng Y, Demura M, Yilmaz B, Martin R, Utsunomiya H, Thung S, et al: Aromatase excess in cancers of breast, endometrium and ovary. J Steroid Biochem Mol Biol 106: 81-96, 2007.

31. Chumsri S and Brodie A: Aromatase inhibitors and breast cancer. Horm Mol Biol Clin Investig 9: 119-126, 2012.

32. Chumsri S: Clinical utilities of aromatase inhibitors in breast cancer. Int J Womens Health 7: 493-499, 2015.

33. Shields-Botella J, Bonnet P, Duc I, Duranti E, Meschi S, Cardinali S, Prouheze P, Chaigneau AM, Duranti V, Gribaudo $\mathrm{S}$, et al: In vitro and in vivo models for the evaluation of new inhibitors of human steroid sulfatase, devoid of residual estrogenic activity. J Steroid Biochem Mol Biol 84: 327-335, 2003.

34. Santner SJ, Ohlsson-Wilhelm B and Santen RJ: Estrone sulfate promotes human breast cancer cell replication and nuclear uptake of estradiol in MCF-7 cell cultures. Int J Cancer 54: 119-124, 1993.

35. Hill SM, Spriggs LL, Simon MA, Muraoka H and Blask DE: The growth inhibitory action of melatonin on human breast cancer cells is linked to the estrogen response system. Cancer Lett 64: 249-256, 1992.

36. Molis TM, Spriggs LL and Hill SM: Modulation of estrogen receptor mRNA expression by melatonin in MCF-7 human breast cancer cells. Mol Endocrinol 8: 1681-1690, 1994.

37. Cos S, Martínez-Campa C, Mediavilla MD and Sánchez-Barceló EJ: Melatonin modulates aromatase activity in MCF-7 human breast cancer cells. J Pineal Res 38: 136-142, 2005.

38. Cos S, González A, Güezmes A, Mediavilla MD Martínez-Campa C, Alonso-González C and Sánchez-Barceló EJ: Melatonin inhibits the growth of DMBA-induced mammary tumors by decreasing the local biosynthesis of estrogens through the modulation of aromatase activity. Int J Cancer 118: 274-278, 2006.

39. González A, Martínez-Campa C, Mediavilla MD, Alonso-González C, Alvarez-García V, Sánchez-Barceló EJ and Cos S: Inhibitory effects of melatonin on sulfatase and $17 \beta$-hydroxysteroid dehydrogenase activity and expression in glioma cells. Oncol Rep 23: 1173-1178, 2010.

40. González A, Alvarez-García V, Martínez-Campa C, Mediavilla MD, Alonso-González C, Sánchez-Barceló EJ and Cos S: In vivo inhibition of the estrogen sulfatase enzyme and growth of DMBA-induced mammary tumors by melatonin. Curr Cancer Drug Targets 10: 279-286, 2010.

41. Santner SJ and Santen RJ: Inhibition of estrone sulfatase and $17 \beta$-hydroxysteroid dehydrogenase by antiestrogens. J Steroid Biochem Mol Biol 45: 383-390, 1993.

42. Li Y, Xu Y, Li X, Qin Y and Hu R: Effects of PPAR- $\alpha$ agonist and IGF-1 on estrogen sulfotransferase in human vascular endothelial and smooth muscle cells. Mol Med Rep 8: 133-139, 2013.

43. Xu Y, Yang X, Wang Z, Li M, Ning Y, Chen S, Yin L and Li X: Estrogen sulfotransferase (SULT1E1) regulates inflammatory response and lipid metabolism of human endothelial cells via PPAR $\gamma$. Mol Cell Endocrinol 369: 140-149, 2013. 